\title{
EDITORIAL
}

\section{Increasing the rigor of obesity research publications}

\author{
International Journal of Obesity (2017) 41, 1159; doi:10.1038/ \\ ijo.2017.118
}

The International Journal of Obesity has had a series of papers in recent months that have dealt with the rigor of research, particularly in the field of obesity. Evaluation of the way obesity scientists do research is uncomfortable and sometimes controversial. $I J O$ is attempting to enhance the quality of research in the field of obesity and will attempt to hold papers accepted to $I J O$ to a higher standard than many other journals.

This issue includes discussion on five papers that deal with research, how research is conducted, and how data are analyzed. ${ }^{1-5}$ Two original papers, one by Mazimba et al. ${ }^{1}$ in this issue and an earlier IJO paper by Bagheri et al., ${ }^{2}$ involve the 'obesity paradox,' a phenomenon that has been generally accepted in the field. An editorial by Banack et al. ${ }^{3}$ expresses the opinion that the 'obesity paradox' does not exist, and papers that report such findings are either interpreting the data incorrectly or using inappropriate statistical analyses. The 'obesity paradox' phenomenon has attracted a great deal of attention in the scientific and lay press, and IJO would like to start a critical discussion on whether it exists and if so, how data should be analyzed to show it.

Another editorial by Robinson et $a l^{4}{ }^{4}$ discusses the issues of body image and informing patients that they are obese. Patients who are told they are obese have poorer outcomes, including more weight gain and depression, than those who are not given this diagnosis. Robinson et al. conclude that informing patients that they are obese is often not beneficial and raises the question that we should not give this diagnosis to patients. They conclude that the obesogenic environment is responsible for the epidemic of obesity, and government action will be needed to solve the problem. Discrimination against obesity is mentioned briefly, but the major problem of how stigma against obesity alters thoughts and behavior of scientists, clinicians and lay people is not explored in depth. It would be unthinkable, for example, because there is stigma against cancer, not to inform a patient that he/she has cancer. Why should obesity be different?

In the final paper of this series, Voss ${ }^{5}$ calls for a more rigorous examination of evidence to support opinions and recommendations in scientific papers. He casts doubt on the common wisdom that the level of food supply in a country is the cause of the increased prevalence of obesity in that country. Military personnel randomly assigned to different countries have a higher rate of obesity in countries with a low food supply and vice versa. He rebuts the conclusion of Robinson et al. that the obesogenic environment is responsible for obesity, and concludes that too much of the 'settled science' in obesity is based on opinion and good intentions rather than hard scientific evidence.

The Editors hope that the papers in this issue and those in the past and future issues of $I J O$ will stimulate scientists to re-evaluate many of the assumptions about obesity, determine those which are truly evidence based, and improve the rigor of science in our journal.

\section{CONFLICT OF INTEREST}

RLA is a consultant to Novo Nordisk and the owner of Obetech LLC, a company that has multiple patents regarding adipogenic adenoviruses and sells a diagnostic assay for adenovirus 36. IAM is a member of Scientific Advisory Boards for Mars Inc, Nestle, IKEA, and a member of the Scientific Advisory Committee on Nutrition for the UK Government's Public Health England.

RL Atkinson ${ }^{1}$ and IA Macdonald ${ }^{2}$ ${ }^{1}$ Division of Endocrinology and Metabolism, Department of Internal Medicine, Virginia Commonwealth University, Richmond, VA, USA and ${ }^{2}$ School of Life Sciences, University of Nottingham, Nottingham, UK E-mail: adv36lab@gmail.com

\section{REFERENCES}

1 Mazimba S, Holland E, Nagarajan V, Mihalek AD, Kennedy JLW, Bilchick KC. Obesity paradox in group 1 pulmonary hypertension: analysis of the NIH-Pulmonary Hypertension Registry. Int J Obes 2017; 41: 1164-1168.

2 Bagheri M, Speakman JR, Shemirani F, Djafarian K. Renal cell carcinoma survival and body mass index: a dose-response meta-analysis reveals another potential paradox within a paradox. Int J Obes (Lond) 2016; 40: 1817-1822.

3 Banack HR, Stokes A. The 'obesity paradox' may not be a paradox at all. Int J Obes 2017; 41: 1162-1163.

4 Robinson E, Haynes A, Sutin AR, Daly M. Telling people they are overweight: helpful, harmful or beside the point? Int J Obes 2017; 41: 1160-1161.

5 Voss JD. On food supply and obesity, missing the point is easy. Int J Obes 2017; 41: 1169-1170. 